\title{
Liquid-Fuel Behavior in an Aeronautical Injector Submitted to Thermoacoustic Instabilities
}

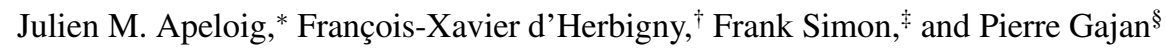 \\ ONERA-The French Aerospace Lab, 31055 Toulouse, France \\ Mikael Orain $\mathbb{1}$ \\ ONERA-The French Aerospace Lab, 91123 Palaiseau, France \\ and \\ Sébastien Roux- \\ SNECMA S.A., 77550 Réau, France \\ DOI: $10.2514 / 1 . B 35290$
}

\begin{abstract}
The aim of this work is to study the role of the liquid phase in the thermoacoustic coupling, which subsequently leads to combustion instabilities. Experimental investigations were performed on an actual multipoint spray injector geometry used in real aeronautical combustors. A test bench was specifically designed with continuously changeable acoustics conditions, which allows obtaining of a stable or an unstable flame for identical flow conditions. Different laser-based visualization techniques were used to analyze the kerosene spray (both liquid and vapor phases) and the heat released from the flame. A phase-averaged data processing of the planar laser-induced fluorescence images reveals the complex unsteady behavior of the liquid phase, its coupling with pressure fluctuations in the chamber, the heat released from the flame. The origins of the spray fluctuations are also analyzed.
\end{abstract}

\begin{tabular}{lll} 
& \multicolumn{1}{c}{ Nomenclature } \\
$D_{\mathrm{REF}}$ & $=$ reference diameter \\
$d A$ & $=$ surface integration variable; $1 \mathrm{~m}^{2}$ \\
$d t$ & $=$ & time integration variable; $1 \mathrm{~s}$ \\
$d V$ & $=$ & volume integration variable; $1 \mathrm{~m}^{3}$ \\
$F$ & $=$ & flame describing function \\
$I$ & $=$ & light intensity over camera dynamics, number of counts \\
$J$ & $=$ & momentum ratio \\
$\dot{m}_{\text {air }}$ & $=$ air mass flow rate, $\mathrm{g} / \mathrm{s}$ \\
$\dot{m}_{f, \mathrm{MP}}$ & $=$ fuel mass flow rate on the multipoint system, $\mathrm{g} / \mathrm{s}$ \\
$\dot{m}_{f, P}$ & $=$ fuel mass flow rate on the pilot system, $\mathrm{g} / \mathrm{s}$ \\
$p^{\prime}$ & $=$ acoustic pressure, $\mathrm{Pa}$ \\
$\bar{p}^{\prime}$ & $=$ averaged pressure, $\mathrm{Pa}$ \\
$q^{\prime}$ & $=$ unsteady heat release, $\mathrm{W} / \mathrm{m}^{3}$ \\
$R a$ & $=$ local Rayleigh index \\
$T$ & $=$ instability cycle period, $\mathrm{s}$ \\
$T_{\text {air }}$ & $=$ air inlet temperature, $\mathrm{K}$ \\
$u^{\prime}$ & $=$ acoustic velocity, $\mathrm{m} / \mathrm{s}$ \\
$\gamma$ & $=$ heat capacity ratio \\
$\Sigma$ & $=$ surface of the control system boundary, $\mathrm{m}^{2}$ \\
$\tau$ & $=$ characteristic time, $\mathrm{s}$ \\
$\Omega$ & $=$ volume of the control system, $\mathrm{m}^{3}$
\end{tabular}

\section{Introduction}

$\mathbf{C}$ OMBUSTION instabilities occurring in industrial-type burners have been identified and studied for many years [1-8]. The phenomena are also called thermoacoustic instabilities because they result from a coupling between the acoustic field pressure and

Received 18 December 2013; revision received 19 June 2014; accepted for publication 27 June 2014; published online 15 October 2014. Copyright (C) 2014 by the authors. Published by the American Institute of Aeronautics and Astronautics, Inc., with permission. Copies of this paper may be made for personal or internal use, on condition that the copier pay the $\$ 10.00$ per-copy fee to the Copyright Clearance Center, Inc., 222 Rosewood Drive, Danvers, MA 01923; include the code 1533-3876/14 and \$10.00 in correspondence with the CCC

*Ph.D. Student, DMAE/MH, 2 av. Edouard Belin. Member AIAA.

${ }^{\dagger}$ Engineer, DMAE/MH, 2 av. Edouard Belin.

*Research Engineer, DMAE/ITAC, 2 av. Edouard Belin.

${ }^{\S}$ Research Engineer, DMAE/MH, 2 av. Edouard Belin.

"Research Scientist, DMPH/SLM, Chemin de la Hunière.

**Engineer, Département Méthodes, Rond-Point René Ravaud. velocity fluctuations (respectively, $p^{\prime}$ and $u^{\prime}$ ) and the unsteady heat release $q^{\prime}$ from a flame. For aeroengine applications, recent economical and environmental requirements [9] have led to the development of innovative combustor concepts with shorter lengths, operating at higher pressure in lean combustion regimes in order to minimize pollutants formation (NOx, soot, etc.). In these new combustion chambers, a higher air mass flow rate is required for fuel atomization and burning; therefore, less air is available for cooling the combustor walls. Consequently, wall multiperforation is generally used for cooling, which modifies the acoustic impedance of the walls. Some of these geometric modifications may enhance the onset of combustion instabilities, which generally lead to large cyclic pressure or velocity fluctuations inside the burner. These can generate important heat transfer at the combustor walls or large-amplitude vibrations of the burner structure. This can result in the damaging of the combustor or even to its destruction, which is incompatible with safety and durability standards required in the aeronautical industry.

To better understand these phenomena and prevent their occurrence, numerous studies (both experimental and numerical) were performed over the years. They started in the early 19th century, when Higgins [10] and Rijke [11] presented two experiments involving thermoacoustic instabilities. Later in that century, Lord Rayleigh [12] proved analytically the existence of such phenomena, and he derived a criterion for their onset. Nowadays, combustion instabilities may be observed in a wide range of applications; one of them is rocket propulsion, which saw in the work of Crocco and Cheng $[13,14]$, proposing the first model of acoustic response of the flame. The coupling can be described as a closed loop of interactions, back and forth, between acoustic and heat release, as schematically represented in Fig. 1 [15]. It was shown in the works of Putman and Dennis $[\underline{16}, \underline{17}]$, or Nicoud and Poinsot [18], that the flame stability depends on an extended Rayleigh criterion that compares the source term of acoustic energy from the flame with the acoustic fluxes at the boundary surfaces, as shown in Eq. (1). The source term depends on the phase relationship between pressure and heat release oscillations in the combustor, which is imposed by the different time delays appearing in the $p^{\prime}-q^{\prime}$ coupling:

$$
\frac{1}{T} \int_{T}\left\{\frac{\gamma-1}{\gamma \bar{p}} \oiiint_{\Omega} p^{\prime} q^{\prime} \mathrm{d} V-\oiint_{\Sigma} p^{\prime} u^{\prime} \mathrm{d} A\right\} \mathrm{d} t>0
$$

In Eq. (1), $\gamma$ is the heat capacity ratio; $p^{\prime}, u^{\prime}$, and $q^{\prime}$ are, respectively, the pressure, velocity, and heat release rate fluctuations; 


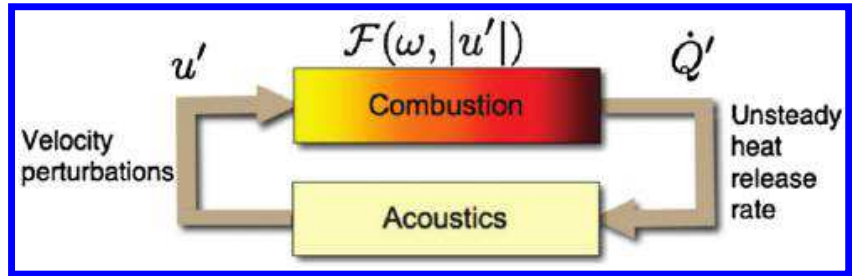

Fig. 1 Principle of thermoacoustic instabilities: resonant interactions between acoustics and combustion. The flame response is conveniently represented in terms of a describing function $F\left(\omega,\left|u^{\prime}\right|\right)[\underline{15}]$.

$T$ is the instability cycle period; and $\bar{p}$ is the average pressure over the system control volume $\Omega$. $\Sigma$ is the system control surface and, finally, $d V$ and $d A$ are, respectively, the volume and surface integration variables.

In Fig. 1, one side of the loop (left) shows unsteady heat release producing pressure (or velocity) fluctuations. Many authors studied this, and descriptions of the various phenomena involved can be found in Ducruix et al. [1] and Lieuwen [2]. Similarly, it was shown in $[3,4]$ that pressure fluctuations could arise when entropy or vorticity waves, coming from the unsteady flame or upstream flow, interact with an abrupt modification of the flow cross section (e.g., nozzle). Note that, in most cases with the Mach number in the combustor being low, the convection of entropy or vorticity waves induces a large time delay between the unsteady heat release $q^{\prime}$ and induces pressure fluctuations $p^{\prime}$ in comparison to the timescale associated with the direct acoustic perturbation produced by the flame.

On the other side of the loop (right), the production of heat release resulting from $p^{\prime}$ or $u^{\prime}$ is not so clear [1] and depends upon the characteristics of the combustion system. A large amount of work has been performed on gas-fueled combustors (premixed or not) in order to describe the phenomena involved and to determine their characteristics in terms of amplitude and time delay, or gain and phase [58,19-24]. In liquid-fueled combustors, thermoacoustic instabilities involve additional complex phenomena such as spray atomization/ vaporization/combustion and their couplings with turbulence, chemistry, flow instabilities, and acoustics. However, in an industrialtype combustor, all these parameters generally interact with each other, which make it difficult to understand the respective influence of each individual parameter. As a result, experiments are mostly performed on simplified geometries in order to understand the specific phenomena linked to liquid-fuel injection. For example, Eckstein et al. [25] analyzed the spray generated by an air-blast system subject to periodic air velocity fluctuations produced by a siren placed upstream of the injector. The authors observed that the droplet size in the spray varied periodically at the same frequency as the velocity excitation. Moreover, they explained that, for a given liquid flow rate, high air velocities produce a large number of small droplets, whereas low air velocities produce a small amount of large droplets. In this way, when combustion instabilities occur, the periodic velocity fluctuations inside the atomizer create a time-varying droplet size distribution, which is transported further downstream to the flame as a droplet wave. During this convection phase, the smalldroplet zones produce a larger amount of fuel vapor than the largedroplet zones. As a result, an equivalence ratio wave appears that interacts with the flame to produce a periodic heat release oscillation. In parallel, Giuliani et al. [26] and Gajan et al. [27] studied spray behavior downstream of both a simplified liquid-fueled atomizer and a airblast type atomizer with a prefilming zone in nonreactive conditions. In the first case, droplets were formed from the disintegration of an axisymmetric liquid sheet sheared internally and externally by two coswirling airflows. In the second case, a prefilming zone was formed before the atomization of the liquid fuel. In both experiments, velocity pulsations were created by a siren placed upstream or downstream of the atomizer. The authors observed the appearance of a droplet density wave transported downstream of the atomization zone. A phase-averaged postprocessing method applied to Fraunhofer-Mie scattering or phase Doppler techniques allowed us to show that the local droplet density waves were mainly linked to an oscillation of the number of small droplets in the size histogram. By using a one-dimensional model based on the Boussinesq-Basset-Oseen transport equation, Giuliani et al. [26] concluded that this phenomenon was due to the influence of the oscillating velocity field on the motion of the small droplets, which segregates them in space and therefore forms droplet concentration waves. Furthermore, they noted that droplets involved had a Stokes number (calculated from the air pulsation period) smaller than 0.2.

Over the last decades, much knowledge on physical phenomena underlying combustion instabilities has been gained. However, additional detailed experimental studies are still required to further understand thermoacoustic instabilities in a realistic liquid-fueled combustion chamber, and subsequently improve the modeling that is implemented into flow numerical simulations. These experiments need to include full characterization of combustor aerodynamics (velocity field measurements), combustor acoustics (flame transfer function measurements), flame structure, and spray properties (measurements of the liquid and vapor phases).

The work presented here had this goal in mind, and a large dataset was obtained from various experimental techniques. In this paper, the results will specifically focus on the role of the spray behavior in thermoacoustic coupling, thanks to a joint analysis of the temporal evolution of the spatial fuel distribution and flame structure along the instability limit cycle.

\section{Test Facility}

The liquid-fueled ONERA thermoacoustic rig (LOTAR) setup is installed on the ONERA LACOM test bench. The air feeding system delivers a mass flow rate up to $1 \mathrm{~kg} / \mathrm{s}$, which can be heated up to $900 \mathrm{~K}$ by a $1 \mathrm{MW}$ electric heater at a maximum pressure of $50 \mathrm{bar}$. The air mass flow rate is measured $( \pm 3.3 \%)$ with a sonic nozzle located downstream of the electric heater. Liquid kerosene is pressurized in two separate tanks and is supplied to the test rig by means of two lines each equipped with a Coriolis flow controller $(0-10 \mathrm{~g} / \mathrm{s} \pm 0.15 \%)$. The global equivalent ratio (GER) of the flow is deduced from these different mass flow rates with an uncertainty of $\pm 3.5 \%$. In the present case, experiments are performed at atmospheric pressure.

A schematic of the LOTAR setup is presented in Fig. 2, where air flows from left to right. It is divided into three parts. The first part (on the left-hand side) comprises a siren, permitting us to force the rig acoustics at different frequencies. It is used to excite the flow during the flame transfer function measurements. Air then flows into a 1-mlong tube (with $50 \mathrm{~mm}$ inner diameter), which is used in order to damp the high-velocity fluctuations obtained at the siren outlet and ensure acoustic propagation with plane waves. This pipe is equipped

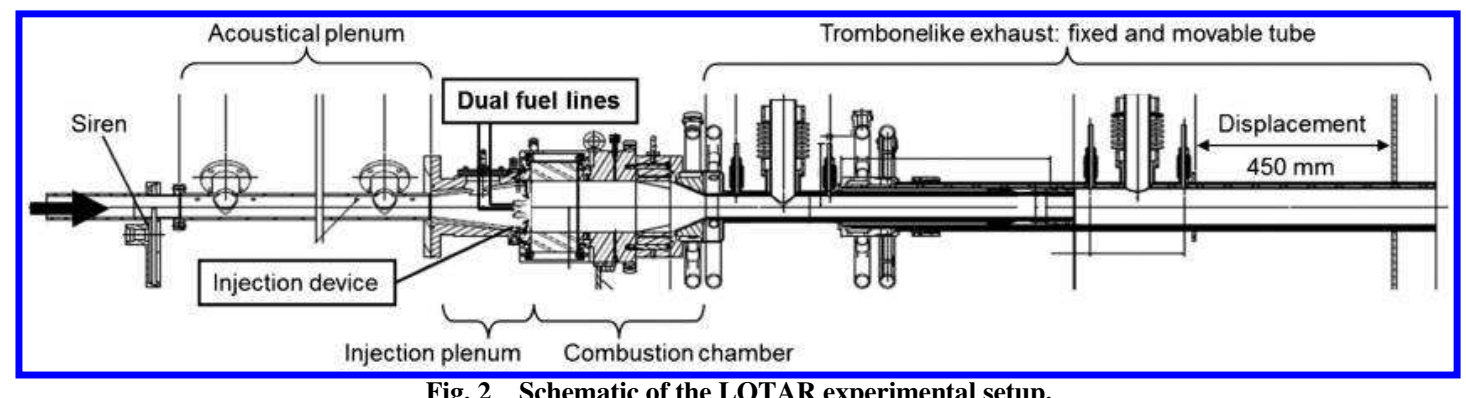

Fig. 2 Schematic of the LOTAR experimental setup. 


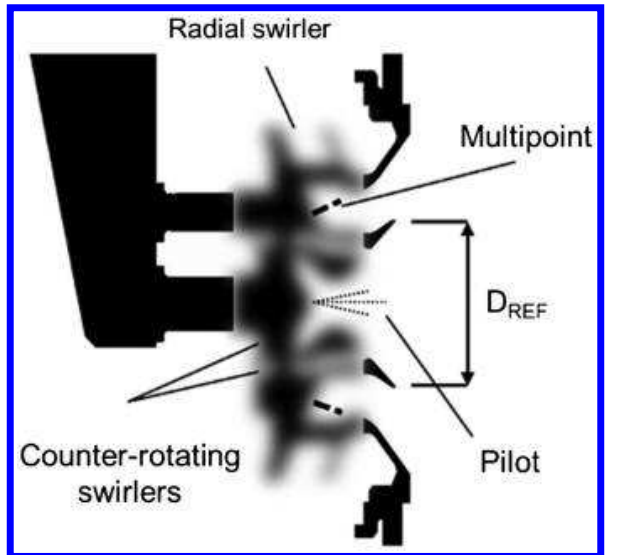

Fig. 3 Schematic of a novel aeroengine injection system used in the experiments.

with four microphone taps used for the acoustic characterization and two intakes to mount a loudspeaker. The second part corresponds to the combustor. It includes a plenum used to mount the injection system (later described) and a water-cooled optical sector equipped with large windows, allowing us to visualize the flow (spray and flame) and to perform optical measurements right at the outlet of the injection system. The last part is a trombonelike section, composed of a fixed tube and a coaxial movable tube. This allows continuous modifying of the inner exhaust length (IEL), in millimeters, defined by the length between the exit plane of the injection system and the exit plane of the movable tube. This length change creates a variation of the natural resonant frequencies of the rig. To limit the mechanical constraints due to the high temperature of the exhaust gases, all this section is water cooled. Similar to the first part upstream of the combustor, this last part is equipped with microphones taps and loudspeaker intakes.

The injection system developed by SNECMA is schematically represented in Fig. 3 . It comprises two injection zones, a pilot zone composed of a pressure atomizer in the center, and a multipoint zone at the periphery. In this zone, the liquid fuel is injected through a set of individual jets in crossflow. Axial and radial swirlers permit us to induce airflow rotation. A perforated plate allows the creation of a cooling film at the periphery of the rig section. The distribution of the fuel between the pilot and the multipoint zone is controlled though a fuel split parameter (FSP) corresponding to the percentage of the overall kerosene mass flow rate going through the pilot zone.

\section{Stability Analysis of the Test Facility}

\section{A. Definition of the Stability Criteria}

As mentioned earlier in this paper, the Rayleigh criterion was extended to include acoustic losses at the system boundaries [16-18], and the formula given in Eq. (1) is well suited for complex combustors. However, the experimental quantification of the various parameters is not straightforward; the measurement of the acoustic losses is very difficult and has to be neglected. Usually, only the first term of this criterion is considered. Samaniego et al. [28] identified the stability regimes from the analysis of the pressure and flame radiation oscillations. From each signal, a stability map was drawn, taking into account a threshold level on the fluctuation amplitude and delimiting the stable/unstable regions. The authors obtained a reasonably good overlapping of the unstable zones deduced from the two signal analysis.

A similar method was used for this study, but the definition of combustion stability is based only on pressure fluctuation measurements. A few preliminary tests showed that combustion instabilities could easily be identified from the spectral analysis of the pressure signal. Three types of power spectrum density (PSD) calculated from signals delivered by the microphone located $266 \mathrm{~mm}$ downstream of the combustion chamber are shown in Fig. 4. In this figure, the air mass flow rate and the IEL parameters are kept constant, whereas the GER and the FSP are varied. For the lower equivalence ratio $(\mathrm{GER}=0.63)$, the flame was stable and only low intensity peaks appeared at $210 \mathrm{~Hz}\left(143 \mathrm{~dB}_{\mathrm{SPL}}\right)$ and $596 \mathrm{~Hz}\left(129 \mathrm{~dB}_{\mathrm{SPL}}\right)$. These two peaks, linked to acoustic longitudinal modes of the test rig, are also present in the two other spectra with low levels $\left(145 \mathrm{~dB}_{\mathrm{SPL}}\right.$ at $220 \mathrm{~Hz}$ and $129 \mathrm{~dB}_{\mathrm{SPL}}$ at $624 \mathrm{~Hz}$ for GER $=0.79$, and $142 \mathrm{~dB}_{\mathrm{SPL}}$ at $224 \mathrm{~Hz}$ and $130 \mathrm{~dB}_{\mathrm{SPL}}$ at $664 \mathrm{~Hz}$ for GER = 1.02). The frequency shifts are due to the change of flame temperature induced by the change of GER. For the two higher equivalence ratios, a new peak with a stronger amplitude appears around $170 \mathrm{~Hz}$. The sound level reaches 149 and $163 \mathrm{~dB}_{\mathrm{SPL}}$ for GER $=0.79$ and 1.02 , respectively. Furthermore, for GER $=1.02$, a harmonic frequency at $352 \mathrm{~Hz}$ is observed. Therefore, two criteria were used to define the flame stability: the sound pressure level of the resonant peak, and the presence of at least one harmonic of the resonant frequency. The amplitude threshold was fixed to $145 \mathrm{~dB}_{\mathrm{SPL}}$. Hence, three flame categories were defined. When both criteria are fulfilled, the flame is classified as "unstable" (e.g., GER = 1.02); when no criteria are satisfied, the flame is classified as "stable" (e.g., GER =0.69); and finally, if only the amplitude criterion is met, the flame is identified as "non-unstable" (e.g., GER = 0.79).

\section{B. Stability Map}

The LOTAR experimental conditions depend on the following adjustable parameters: 1 ) air mass flow rate $\dot{m}_{\text {air }} ; 2$ ) air inlet temperature $T_{\text {air }}$;3) global equivalent ratio; 4) fuel split parameter; and 5) inner exhaust length.

Other parameters can be of valuable importance in the occurrence of combustion instabilities, such as pressure [29], but they are not investigated in the present study. Moreover, for the purpose of this study, some of the aforementioned parameters were fixed. The air mass flow rate was chosen to be constant at $100 \mathrm{~g} / \mathrm{s}$, and the air inlet temperature was set to $473 \mathrm{~K}$. Only the two extreme IEL values (1955

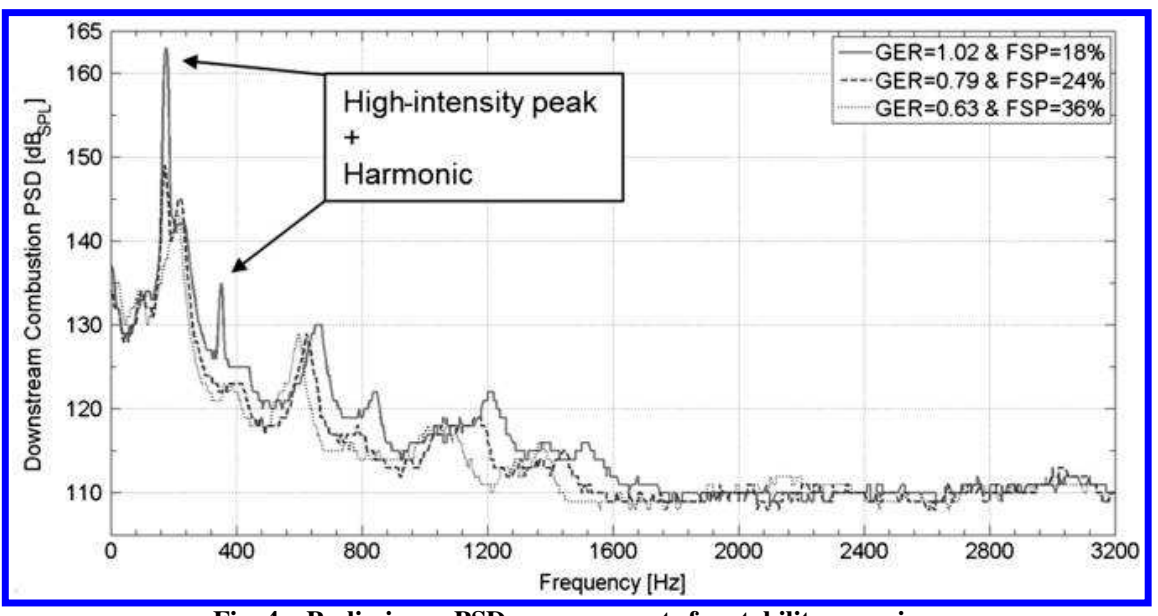

Fig. 4 Preliminary PSD measurements for stability mapping. 


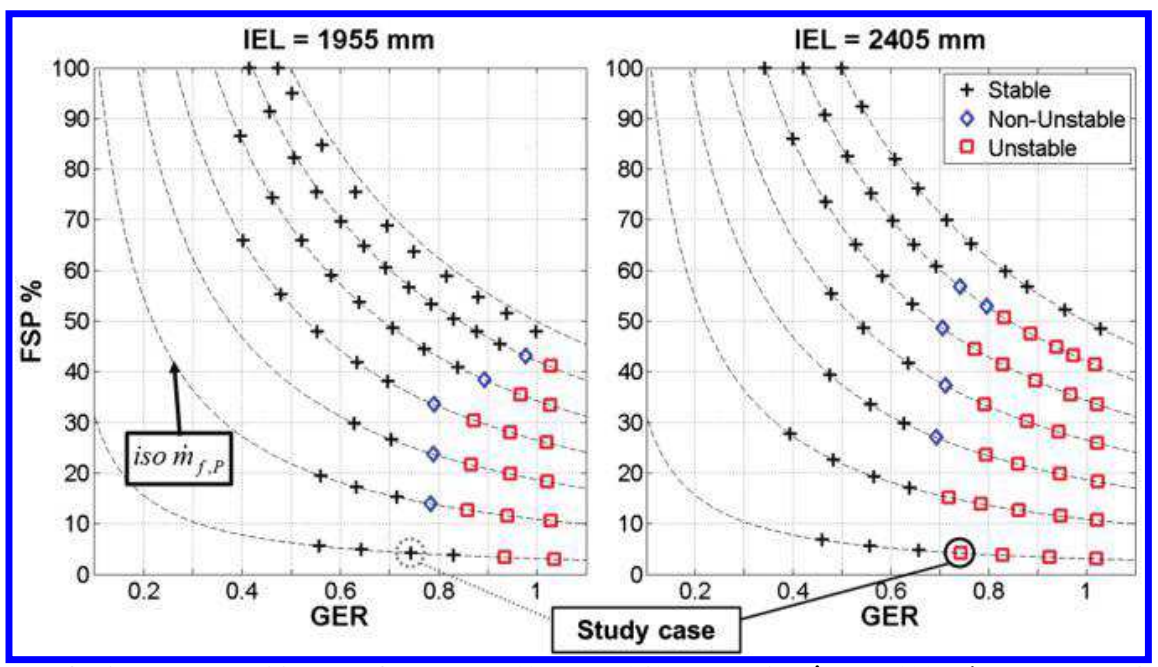

Fig. 5 LOTAR setup stability map for $I E L=1955$ and $2405 \mathrm{~mm}$, with $\dot{m}_{\text {air }}=100 \mathrm{~g} / \mathrm{s}$ and $T_{\text {air }}=473 \mathrm{~K}$.

and $2405 \mathrm{~mm}$ ) were considered. GER was varied from slightly above stoichiometry to extinction value, and FSP varied from 0 to $100 \%$.

Maps were obtained by fixing the fuel mass flow rate of the pilot system $\dot{m}_{f, P}$ and decreasing the fuel mass flow rate feeding the multipoint system $\dot{m}_{f, \text { MP }}$ so that the GER decreased from slightly above stoichiometry to extinction value.

The maps obtained for both IEL values are presented in Fig. 5. The dashed lines correspond to constant fuel mass flow rates through the pilot injector. The upper right-hand side of the maps does not contain any data due to limitations on the fuel mass flow rate of the pilot supply line. On the left-hand side of the maps, the extinction limit occurs for GER $\sim 0.4$ with this airflow condition. It is noticeable that the uppermost line is always stable, which means that instabilities no longer appear if the fuel mass flow rate of the pilot injector is large enough. The unstable cases correspond to the region of higher global equivalent ratios, which is larger for IEL $=2405 \mathrm{~mm}$. As a result, for some flow conditions, the flame changes from the stable to the unstable regime by modifying the IEL value. This occurs for GER = 0.76 and FSP $=4 \%$, which will be referred to hereafter as the study case.

To verify the difference of flame behaviors between the two IEL values, chemiluminescence and planar imaging were obtained with a high-speed Phantom V5 video camera. For the first visualization technique, an interference optical filter [full width at half-maximum $(\mathrm{FWHM})=20 \mathrm{~nm}]$ centered on the $\mathrm{OH} *$ radical emission (at $307 \mathrm{~nm}$ ) was mounted in front of the UV lens placed on a high-speed intensified camera (gate $=400 \mu \mathrm{s}$ ) assembled with the camera. For the second technique, the spray behavior was visualized using a laser sheet delivered by a Quantronix high-speed pulsed laser (Nd: YAG at $527 \mathrm{~nm}, 20 \mathrm{~mJ}$ per pulse), which was synchronized with the camera. For both techniques, the camera frequency was tuned to eight times the combustion instability frequency (i.e., $1440 \mathrm{~Hz}$ ). An example of a sequence of instantaneous images recorded for stable (IEL $=1955 \mathrm{~mm}$, upper rows) and unstable (IEL $=2405 \mathrm{~mm}$, lower rows) flames, with $\dot{m}_{\text {air }}=100 \mathrm{~g} / \mathrm{s}$; GER $=0.76$ and FSP: $4 \%$, is shown in Fig. 6. For the stable case, the flame remains at a fixed position in the combustor. By contrast, for the unstable case, images show simultaneous large spatial variations of the $\mathrm{OH} *$ emission and spray behavior corresponding to cyclic arrival of liquid fuel in the chamber. A spray angle calculation performed on both image sequences is plotted in Fig. 7. This figure clearly shows that the spray angle remains constant for the stable case. By contrast, for the unstable case, the spray angle exhibits large variations $(\sim 8 \mathrm{deg})$ along the instability cycle, which are well correlated with flame motion back and forth.

\section{Simultaneous Planar Laser-Induced Fluorescence on Kerosene Fuel and $\mathrm{OH}$ radical}

\section{A. Apparatus and Procedure}

Laser-induced fluorescence (LIF) is a resonant spectroscopic technique based on the absorption of the incident laser light by molecules, which are promoted to a higher-energy level, when the laser wavelength is tuned to a resonance between an excited state and

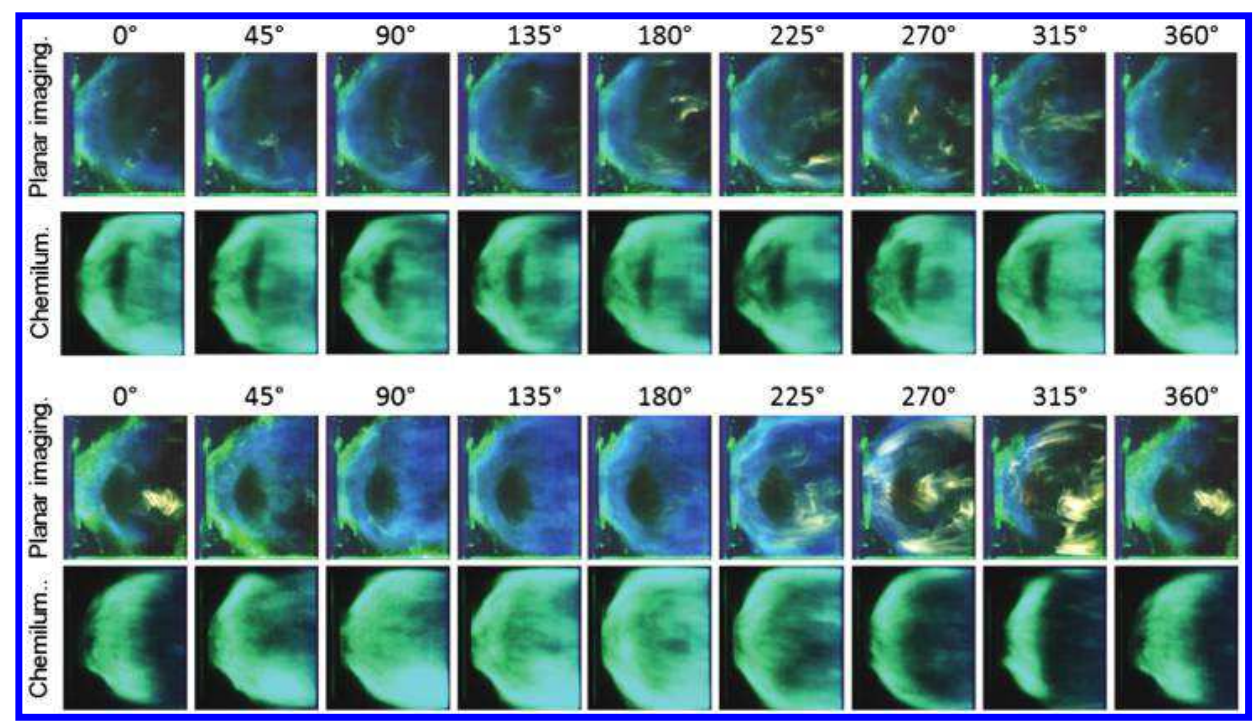

Fig. 6 Images sequence of the spray planar imaging and the flame $\mathrm{OH} *$ chemiluminescence for stable and unstable flames. 


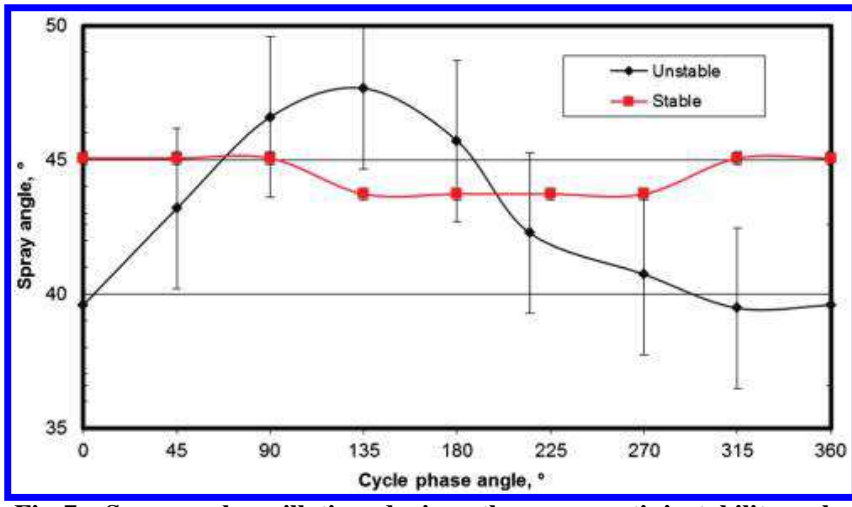

Fig. 7 Spray angle oscillations during a thermoacoustic instability cycle.

state lower energy $[30,31]$. It can be used to measure the temperature and/or species molar fraction by means of different strategies (single or multiple excitation scheme, single or multiple detection scheme). Although LIF was initially a pointwise measurement technique, it has been extended to instantaneous two-dimensional (2-D) characterizations by the use of cameras [planar LIF (PLIF)]. In combustion experiments, the PLIF technique has often been applied to map the $\mathrm{OH}$ radical in a flame [32,33]. Recently, this technique was developed to measure the kerosene concentration in sprays [34,35]. On the LOTAR setup, spatial distributions of both the kerosene fuel and $\mathrm{OH}$ radical were simultaneously measured using PLIF.

Measurements of the $\mathrm{OH}$ radical were performed using a frequency-doubled Q-switched Nd:YAG laser that pumped a dye laser. The dye laser was frequency doubled to deliver wavelengths in the $280-290 \mathrm{~nm}$ spectral range. The dye laser was tuned to $282.75 \mathrm{~nm}$ to excite the $Q_{1}(5)$ line of the $(1,0)$ band of the $\mathrm{OH}\left(X^{2} \Pi-\right.$ $A^{2} \Sigma \perp+$ ) system. Part of the laser beam was directed to the burned gases of a reference laminar methane/air flame in order to tune the laser wavelength to the aforementioned $\mathrm{OH}$ transition. This $\mathrm{OH}$ transition was chosen because of its high intensity, its well-isolated spectral feature, and its low dependence upon temperature. Laser energy was fixed to $10 \mathrm{~mJ}$. Measurements of kerosene fluorescence used a single-excitation scheme, which involved a frequencyquadrupled Nd:YAG laser generating $50 \mathrm{~mJ}$ pulses at $266 \mathrm{~nm}$. The energy of both laser beams was monitored during the experiments by means of laser power meters, and fluctuations were of the order of $5 \%$. The time delay between the two laser beams was fixed to $500 \mathrm{~ns}$ in order to avoid crosstalk between fluorescence signals of $\mathrm{OH}$ and kerosene. This duration is much shorter than the typical flow timescale $(\sim 1.5 \mathrm{~ms})$, ensuring that images of $\mathrm{OH}$ and kerosene fluorescence were representative of the same phenomenon at the time of recording.

Both laser beams were transported via optical mirrors around the LOTAR facility and superimposed with a combination of dichroic mirrors. They were then transformed into two superimposed collimated sheets using a unique set of cylindrical and spherical lenses. The two cylindrical lenses formed a telescope, which spread the beams into collimated sheets. Only the central zone of the laser sheets was used to obtain laser sheet energy profiles that were as flat as possible, allowing, in a first assumption, proportionality between the fluorescence signals and the probe species concentration. A spherical lens with $1 \mathrm{~m}$ focal length finally focused the two sheets to a $150 \mu \mathrm{m}$ waist located in the center of the combustion chamber, along its vertical axis. The laser sheets propagated through the combustor from top to bottom. With this optical setup, only axial measurements could be performed. Energy in the laser sheet was maintained to $5 \mathrm{~mJ}$ for $\mathrm{OH}$ and $25 \mathrm{~mJ}$ for kerosene detection.

Fluorescence from $\mathrm{OH}$ radicals was recorded with a 16-bit intensified charge-coupled device (CCD) camera, whereas another intensified CCD (Fig. 8) simultaneously recorded fluorescence from kerosene vapor and liquid phases. The camera used for $\mathrm{OH}$ visualization had a CCD array of $1024 \times 1024$ pixels and a temporal gate of $60 \mathrm{~ns}$, with a framing rate of $4 \mathrm{~Hz}$, and it used a $105 \mathrm{~mm}, \mathrm{f} / 4.5 \mathrm{UV}$ NIKKOR lens. The cameras used for kerosene detection had a CCD

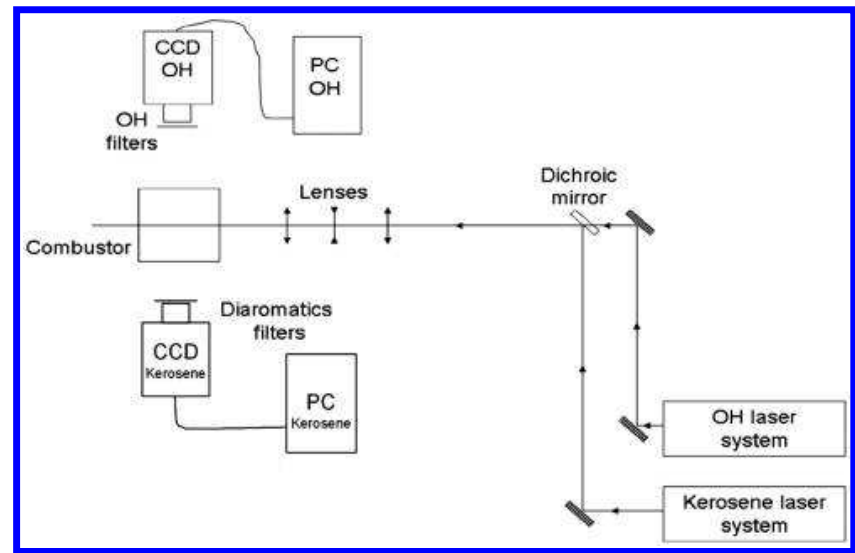

Fig. 8 PLIF apparatus for simultaneous measurements on the kerosene and $\mathrm{OH}$ radical.

array of $512 \times 512$ pixels and a temporal gate of $60 \mathrm{~ns}$, with a framing rate of $4 \mathrm{~Hz}$, and it was equipped with a $\mathrm{f}=94 \mathrm{~mm}$ achromatic $\mathrm{UV}$ lens (Cerco). For $\mathrm{OH}$ measurements, the camera had a combination of colored glass filters (WG 295 and UG 5 from Schott) and a custommade interference filter centered at $310 \mathrm{~nm}(\mathrm{FWHM}=5.6 \mathrm{~nm}, 60 \%$ transmission). For kerosene measurements, the camera used a combination of colored glass filters (high-pass and bandpass filters) to collect wavelengths above $320 \mathrm{~nm}$, which correspond to the fluorescence of diaromatics molecules only. This way, the crosstalk between fluorescence signals from $\mathrm{OH}$ radicals and kerosene was limited. The gain of the intensifiers was tuned in order to use the whole dynamic range of the 16-bit cameras (0-65,535 counts) without saturation effect. Each camera was connected to a computer (called $\mathrm{PC}$ in Fig. 8) that controlled the device and recorded the images. To synchronize all the measurements, the gate-opening signal from the kerosene camera was recorded on the acquisition board of the LACOM bench (National Instruments PXI), which simultaneously recorded the pressure signal from the combustion chamber. This acquisition frequency was set to $10 \mathrm{kHz}$ to ensure the retrieval of the phase of each fluorescence image in the instability cycle.

\section{B. Processing Techniques}

The PLIF apparatus used for this work allows image recording up to $4 \mathrm{~Hz}$, whereas the combustion instability frequency is around $180 \mathrm{~Hz}$. To extract the temporal sequence of events leading to combustion instabilities, a statistical analysis of experimental data is then needed. The phase-averaged analysis is the most common method to study cyclic phenomena: in particular, in combustion experiments $[5,36-41]$. Nonetheless, a periodical reference signal is needed to perform this analysis. This signal is either a pure periodic wave issued from an excitation signal for forced experiments or, in most self-sustained cases, a pseudoperiodic wave representative of the instability studied (e.g., pressure, temperature, light emission, etc.). In this study, the pressure inside of the combustion chamber is chosen as the reference signal. Once the signal is defined, there are two main ways to proceed: the online method, using the "sample and hold" technique, or the postprocessing technique. The first method used by Poinsot et al. [5] processes instantaneously the reference signal to find the zero-crossing time, and it uses an analogical device to delay the acquisition by a specified time shift. However, any analysis mistake cannot be corrected a posteriori, and variations in the instability frequency cannot be taken into account. These drawbacks are avoided by the second method [40], which is better suited for selfsustained thermoacoustic instabilities: for example, to obtain the phase of the $\mathrm{OH} *$ chemiluminescence measurements by using the Hilbert transform [42]. In the present work, the pressure signal is sampled at $10 \mathrm{kHz}$ simultaneously with a transistor-transistor logic (TTL) signal delivered by the cameras. It is first analyzed using a fast Fourier transform algorithm to obtain the instability frequency. Then, a bandpass Butterworth filter of the second order, with a width of $\pm 25 \mathrm{~Hz}$ around the thermoacoustic instability frequency, is applied in order to eliminate high and low frequencies. A zero-crossing 
detection with a positive gradient permits us to identify the beginning and the ending of each instability cycle. By comparing these events with the TTL signal delivered by the cameras, the phase position in the instability cycle of each acquired image is identified with an accuracy of $\pm 1 \mathrm{deg}$.

To extract information about the different phenomena involved in combustion instabilities, raw PLIF images have to be processed. The first step of image processing consists of subtracting the background noise due to laser scattering at the walls, background luminosity due to flame emission, etc. As a result, the signal observed on the background-subtracted PLIF images corresponds only to fluorescence intensity from the kerosene or $\mathrm{OH}$ radical, although electron noise may also have a marginal contribution, as will be discussed later.

PLIF on kerosene is generally $[34,35]$ used to observe kerosene vapor in order to determine a local equivalent ratio. However, when droplets are present in the flow, high fluorescence levels are emitted from the liquid phase at the same wavelength as the vapor fluorescence. In a first approximation, the fluorescence signal emitted from droplets is proportional to their volume [43], but it also depends on other parameters such as laser intensity, liquid temperature, etc. It is, therefore, necessary to apply an intensity threshold level in order to discriminate the liquid and the vapor phases of the fuel on kerosene fluorescence images. The spatial distribution of liquid fuel is determined by considering that all pixels for which the intensity level is above a given threshold correspond to the liquid phase, whereas the remaining pixels are set to zero. After analyzing a large set of images, by investigating the gradient of the fluorescence emission around droplets, the threshold is set to $15 \%$ of the camera dynamic range, and this threshold must be adjusted to $24 \%$ for dense spray. In the current experiments, the differentiation between dense and dilute sprays relies on a fluorescence intensity criterion: an image is considered to show a dense spray when its global intensity is greater than $300 \times 10^{6}$ counts. This adjustment is necessary because the fluorescence signal from an out-of-focus droplet may be similar to the fluorescence signal generated by the vapor, and there are more out-of-focus droplets in a dense spray. In a similar way, kerosene PLIF images yield information on fuel vapor. The spatial distribution of fuel vapor is determined by considering that all pixels for which the intensity level is below a given threshold correspond to the vapor phase, whereas the remaining pixels are set to zero. In this case, the threshold levels are set to $12 \%$ of the camera dynamic range and $18 \%$ for a dense spray. The gap between the liquid and vapor thresholds, arbitrarily chosen, facilitates the interpretation of results when image-averaging operators are used by limiting the overlapping between adjacent areas. Finally, both instantaneous thermodynamic states of kerosene can be plotted simultaneously in the same figure by rescaling the result of each processing on 8-bit levels and attributing these values to one of the three red, green, or blue colors. The result of this process is shown in Fig. 9, where the raw image is presented on the left-hand side, whereas the image on the right-hand side represents the processed data, with the liquid phase in blue and the vapor phase in red.
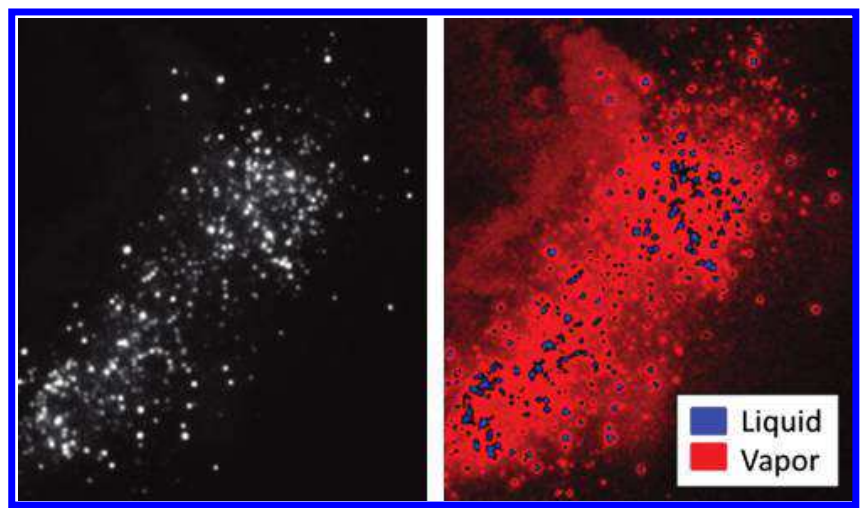

Fig. 9 Threshold processing on a sample image of PLIF on kerosene fuel revealing liquid (blue) and vapor (red) states.
In a similar way, the OH-PLIF images require some processing in order to extract information on the flame front structure. In this study, the goal is to use the $\mathrm{OH}$ radical fluorescence in order to obtain an equivalent unsteady heat release rate as used in various works $[44,45]$. However, to accomplish this, it is important to notice that the $\overline{\mathrm{OH}}$ radical is present in the flame front as well as in the burnt gases. Examination of the $\mathrm{OH}$ fluorescence images shows that using a threshold level around $40 \%$ of the maximum emitted fluorescence signal would remove the $\mathrm{OH}$ radical data from the burned gases region on the OH-PLIF images. Therefore, this threshold is applied to the raw OH-PLIF images, and it allows us to track the only OH radical present in the flame front. This approach is similar to that developed by Yamada et al. [46].

Finally, the processed single-shot PLIF images (both kerosene fuel and $\mathrm{OH}$ radical) are sorted out into 24 equally spaced (every $15 \mathrm{deg}$ ) phase bins from 0 to $360 \mathrm{deg}$ with a tolerance of $\pm 1 \mathrm{deg}$, which allows obtaining of the phase-averaged mean fluorescence image over 100 PLIF images per phase bin (converged statistics).

Although the current measurements intend to not relate fluorescence intensity (in counts) to species concentration (in molecules per cubic centimeters) in a quantitative manner, some words are required on the measurements uncertainty. First of all, as mentioned previously, in each pixel of the background-subtracted PLIF images, the electron noise is of the order of a few counts, whereas the fluorescence signal of kerosene can reach values as high as $\sim 10,000$ counts for the vapor phase and $\sim 55,000$ counts for the liquid phase. However, very low concentrations of kerosene vapor can yield fluorescence signals of a few counts (signal-to-noise ratio $\sim 1$ ), which cannot be separated from the electron noise. Despite the fact that pixels with such a low intensity add an extremely marginal contribution to the signal of the PLIF images, a lower threshold level corresponding to $0.02 \%$ of the camera dynamic range (i.e., signal-tonoise ratio 3) is applied to each background-subtracted PLIF image (before the phase-averaging process) in order to remove this potential minor bias. Pixels with an intensity below this threshold level are set to zero. As a result, the images presented in the following are free of noise and are representative of the sole fluorescence from the kerosene and $\mathrm{OH}$ radical. Second, although laser energy fluctuations are about 5\%, single-shot PLIF images are not corrected for these variations that are randomly distributed over time (similarly to the recording of PLIF images along the instability cycle), so that they are likely to cancel out in the phase-averaging process. Nonetheless, in the worst case, the uncertainty on the fluorescence intensity measurements can be estimated as 5\%, which has a marginal influence on the temporal evolution of the spatial distribution of fuel and flame front structure along the instability cycle. Of course, if quantitative information on species information was sought, uncertainty on concentration values would be higher.

\section{Results and Discussions}

In a first step, the unsteady behaviors of the different quantities (liquid, vapor, and $\mathrm{OH}$ radical) are analyzed separately, and then the correlations between them are investigated.

Twenty-four phase-averaged images of the spatial distribution of the liquid phase at the outlet of the injection system are presented in a strip view of the instability cycle in Fig. 10. A few conclusions can be drawn from Fig. 10. First, only the fuel injected through the multipoint circuit can be visualized on the images, which indicates that the fuel issued from the pilot circuit is burned immediately at the outlet of the pilot injector (i.e., upstream of the area visualized by PLIF). This result is different from findings of Orain et al. [34], obtained in a previous test campaign on the same injection system, where simultaneous fuel patterns generated by both the pilot and the multipoint injector were observed with FSP $=50 \%$ at a pressure of 9.5 bar. Second, it is noticeable that the spray pattern fluctuates to a large extent, both spatially and in terms of fluorescence intensity, over the instability cycle. In particular, a little amount of liquid fuel is observed at phase angles between 210 and 255 deg. Third, three distinct droplet fluxes are identified in Fig. 10, with their maximal intensity occurring at different phase angles $(\overline{90}, 105$, and $315 \mathrm{deg}$ for 


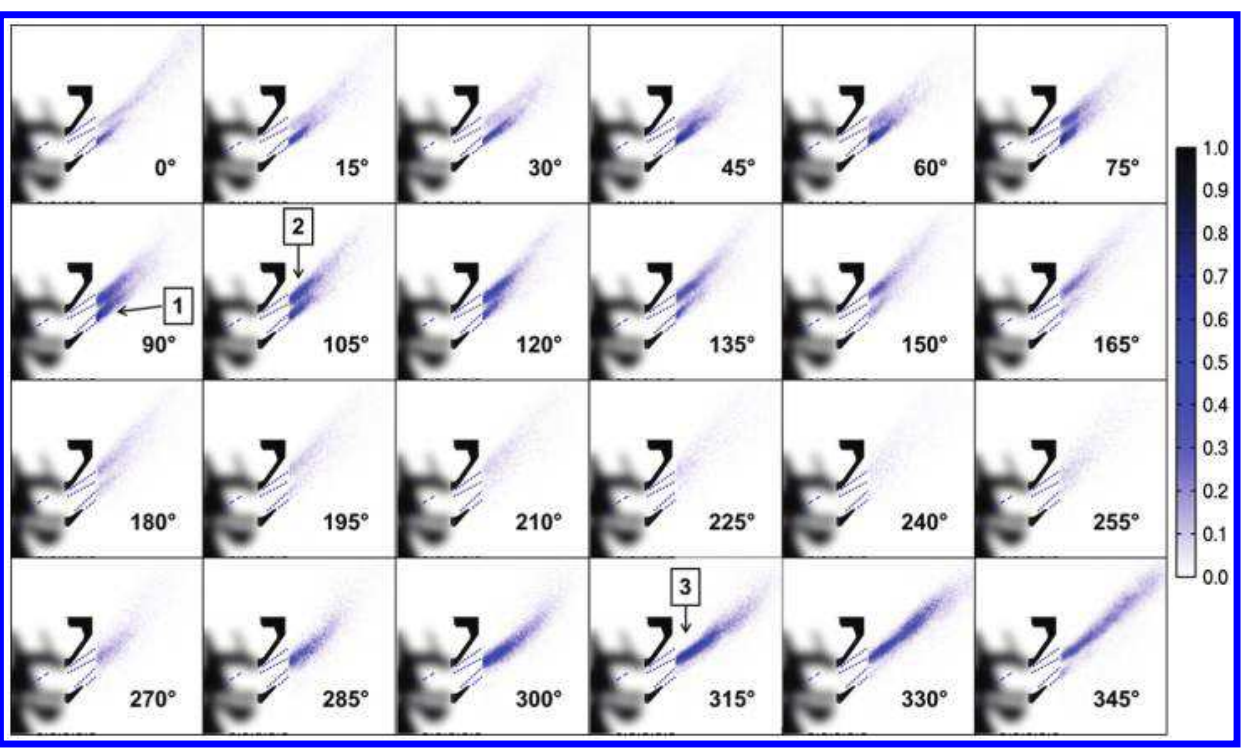

Fig. 10 Temporal sequence of the liquid kerosene spatial distribution during an instability cycle using phase-averaged analysis on PLIF images.

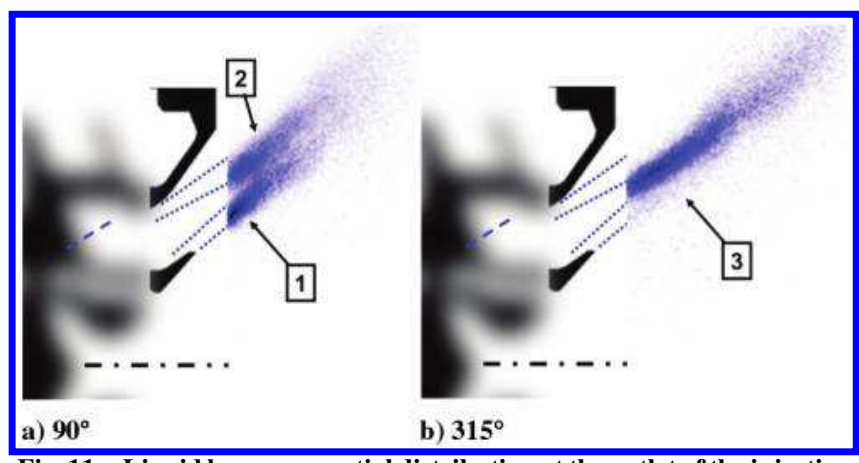

Fig. 11 Liquid kerosene spatial distribution at the outlet of the injection system for cycle phase angles of a) $90 \mathrm{deg}$, and b) $315 \mathrm{deg}$.

fluxes 1,2 , and 3 , respectively). As can be seen, droplet distribution gradually shifts from flux 1 to flux 2 between 0 and $165 \mathrm{deg}$, and then to flux 3 at $270 \mathrm{deg}$. A close-up is presented in Fig. 11 to show the different trajectories of these three fluxes. At the cycle phase angle of $90 \mathrm{deg}$, it is possible to observe fluxes 1 and 2 atomizing from, respectively, the inner and outer walls of the radial swirler (Fig. 11a), whereas the third flux has a trajectory emerging in between these two walls at a cycle phase angle of $315 \mathrm{deg}$ (Fig. 11b).

These three cyclic phenomena can be explained by the unsteady behavior of the crossflow atomizing the liquid jets in the multipoint zone, as presented in the schematic scenario in Fig. 12. This behavior is linked with airflow fluctuations inside the injector through the momentum flux ratio $J$ defined by the momentum flux of the liquid jet with respect to the momentum flux of the crossflow. When the momentum flux of the crossflow is greater than the momentum flux of the liquid jet $(J<1)$, the atomization process results in the liquid jet and droplets hitting the inner wall of the radial swirler, producing a liquid film that is subsequently atomized at the edge of the diffuser. This phenomenon corresponds to the first spray pattern (flux 1) and has a characteristic time $\tau_{1}$. When the momentum ratio reaches a value large enough, the kerosene jet hits the outer wall of the radial swirler, forming a liquid film that is re-atomized further downstream, as well as generating droplets rebounds at the wall. From the geometry of the injection device used for this study and the data published by Lubarsky et al. [47], calculations showed that kerosene fuel impacts the upper wall for liquid jet to air flux ratios above 60 . This phenomenon explains the second spray pattern (flux 2), which has a characteristic time $\tau_{2}$. The third spray pattern (flux 3 ) requires further investigations: it may be that liquid fuel is directly transported to the combustor without hitting the walls of the multipoint circuit and/or a combination of the two previous flux patterns. This pattern occurs for a momentum ratio between the two extreme conditions defined $(1>J>60)$, and it has a characteristic time $\tau_{3}$. The three characteristic times are different and vary due to the diverse convective mechanisms involved in the liquid atomization and transport from its injection point inside of the injector (wall filming or droplet transport) to the combustor. Nevertheless, it is difficult to determine the respective values of $\tau_{1}, \tau_{2}$, and $\tau_{3}$ without droplet velocity measurements inside the multipoint zone.

The behavior of the liquid kerosene observed here leads us to focus on the multipoint circuit spray because, as mentioned previously, the fuel injected through the pilot system is burned before entering the flow area where PLIF measurements are performed, due to the low FSP (i.e., 4\%) used in the current experiments. However, despite this low fuel mass flow rate, it does not mean that the pilot injector is not involved in thermoacoustic instabilities.

The results of the phase-averaged analysis applied to kerosene vapor and $\mathrm{OH}$ radical images are plotted in Figs. 13 and 14, respectively. The 24-image strip of kerosene vapor is similar to that of the liquid phase. The vapor shows the highest levels around the liquid phase, and therefore follows the same cycle. Large fluctuations of the spatial distribution of kerosene vapor are observed in terms of the surface covered and trajectory.

By contrast, the $\mathrm{OH}$ radical fluorescence does not reveal a corresponding large flame front displacement. Nevertheless, a fluctuation of the $\mathrm{OH}$ intensity is observed with a maximum around $45 \mathrm{deg}$ and a minimum value obtained around $225 \mathrm{deg}$. This last value corresponds

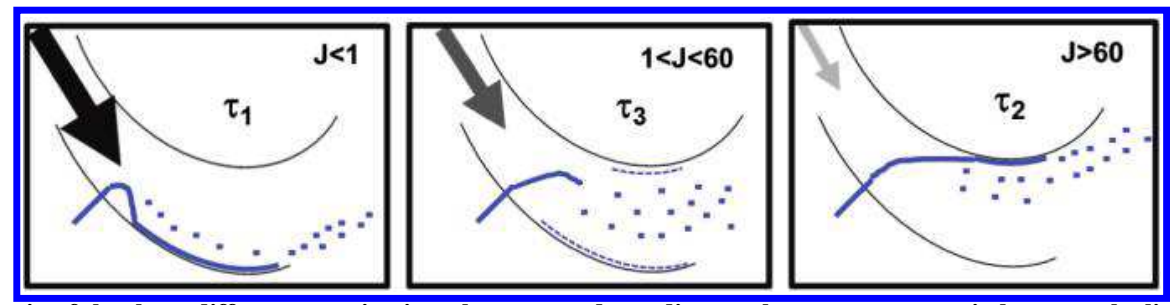

Fig. 12 Schematic scenario of the three different atomization phenomena depending on the momentum ratio between the liquid jet and the crossflow. 


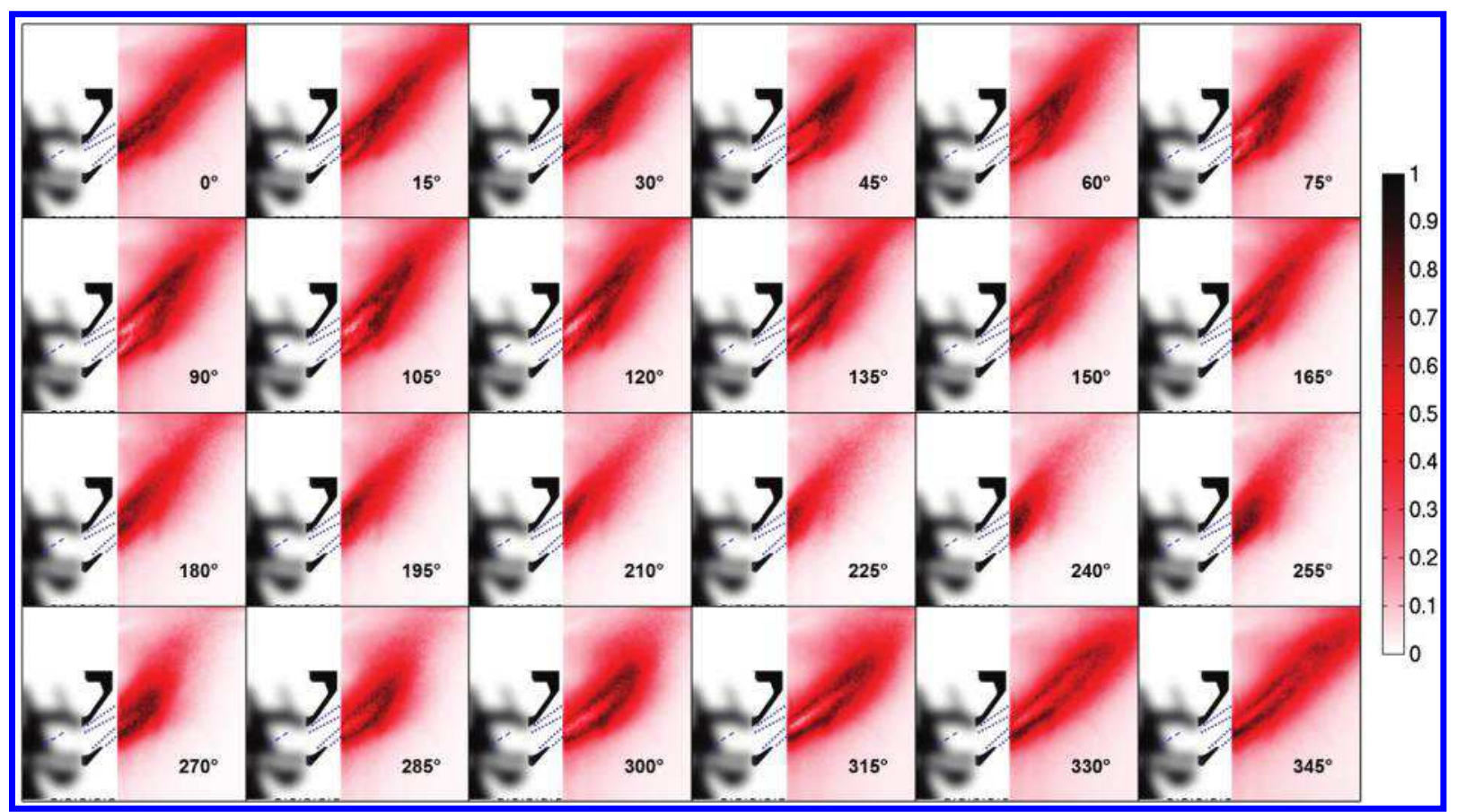

Fig. 13 Temporal sequence of the kerosene vapor spatial distribution during an instability cycle using phase-averaged analysis on PLIF images.

to a phase angle where a little amount of fuel is available to burn in the combustor, which indicates that the heat released by the flame (represented by $\mathrm{OH}$ fluorescence intensity [48]) is spatially well correlated with the fuel quantity.

To gain a better understanding of the timing between the different events revealed by the previous analysis, a spatial averaging of each phase-averaged field is performed. In Fig. 15 , for each quantity (pressure, liquid, vapor, and $\mathrm{OH}$ ), the intensity fluctuations are normalized by the respective average value calculated over the cycle. The pressure fluctuation in the chamber is represented in this figure to help the phase shift comparison between the various quantities. It can be conveniently seen that the liquid and the vapor signal are in phase. The $\mathrm{OH}$ signal in the first half of the cycle (i.e., up to $225 \mathrm{deg}$ ) is also in phase with kerosene (both liquid and vapor phases), whereas a phase shift between $\mathrm{OH}$ and kerosene signals is observed in the second half (i.e., above $225 \mathrm{deg}$ ). Finally, when comparing these three signals to the pressure signal, it appears that the arrivals of the first and second liquid patterns in the chamber revealed by the phaseaveraged images contribute to in-phase oscillations of pressure and heat release, which leads to an amplification of the thermoacoustic instabilities; whereas the third liquid pattern could act as a damper.

Finally, the local Rayleigh distribution calculated from Eq. (2) is applied to the $\mathrm{OH}$ fluorescence results, similar to the work of Samaniego et al. [28] and Lee et al. [44]. The computation of the local values is performed pixel by pixel, and it yields the Rayleigh distribution displayed in Fig. 16. For this representation, negative index values are in black, positives are in red, and neutrals are in white. Positive local Rayleigh index values mean that the local fluctuation of the unsteady heat release is in phase with the pressure fluctuation, and therefore contributes to the combustion instability.

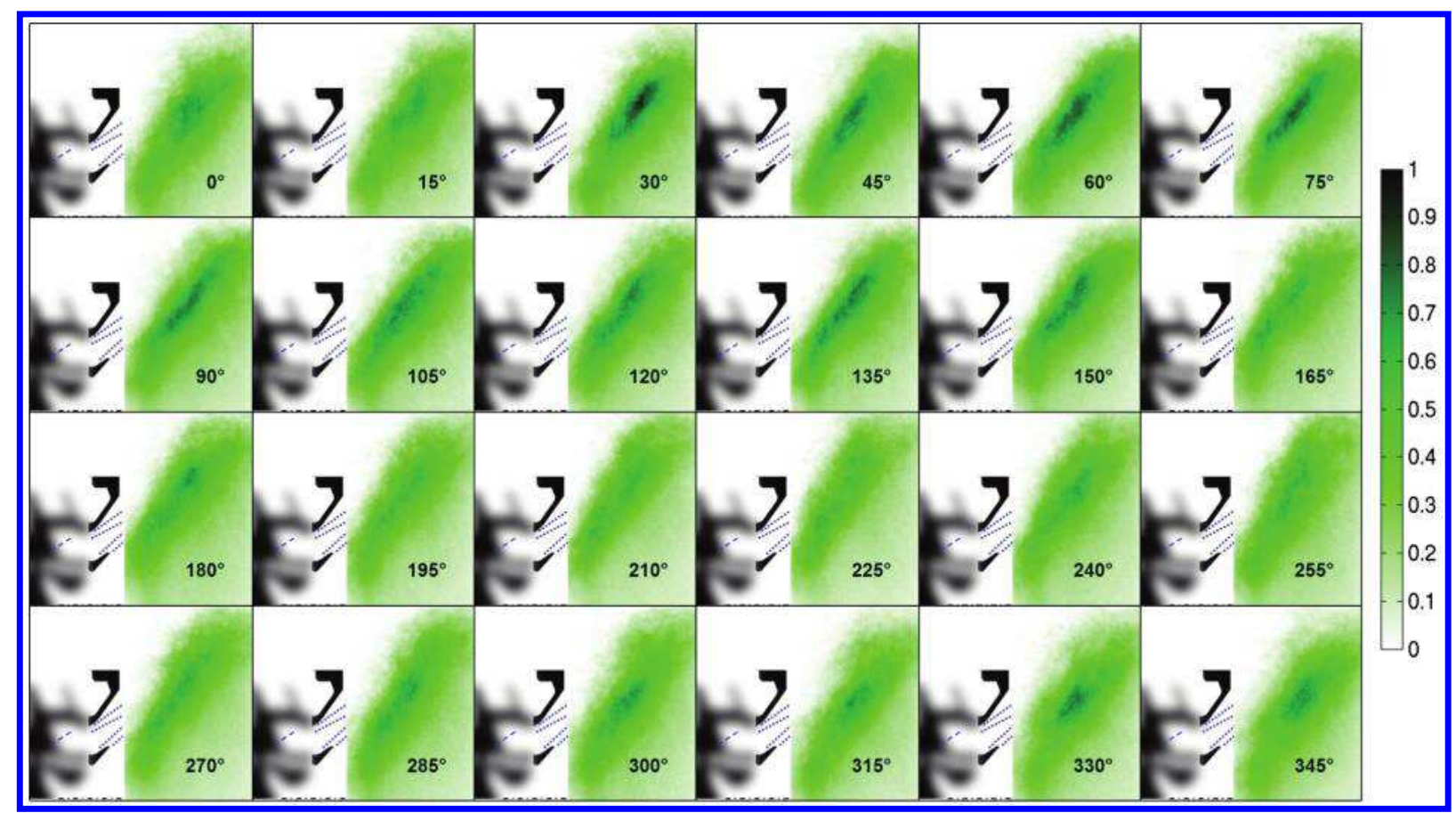

Fig. 14 Temporal sequence of the $\mathrm{OH}$ radical spatial distribution during an instability cycle using phase-averaged analysis on PLIF images. 


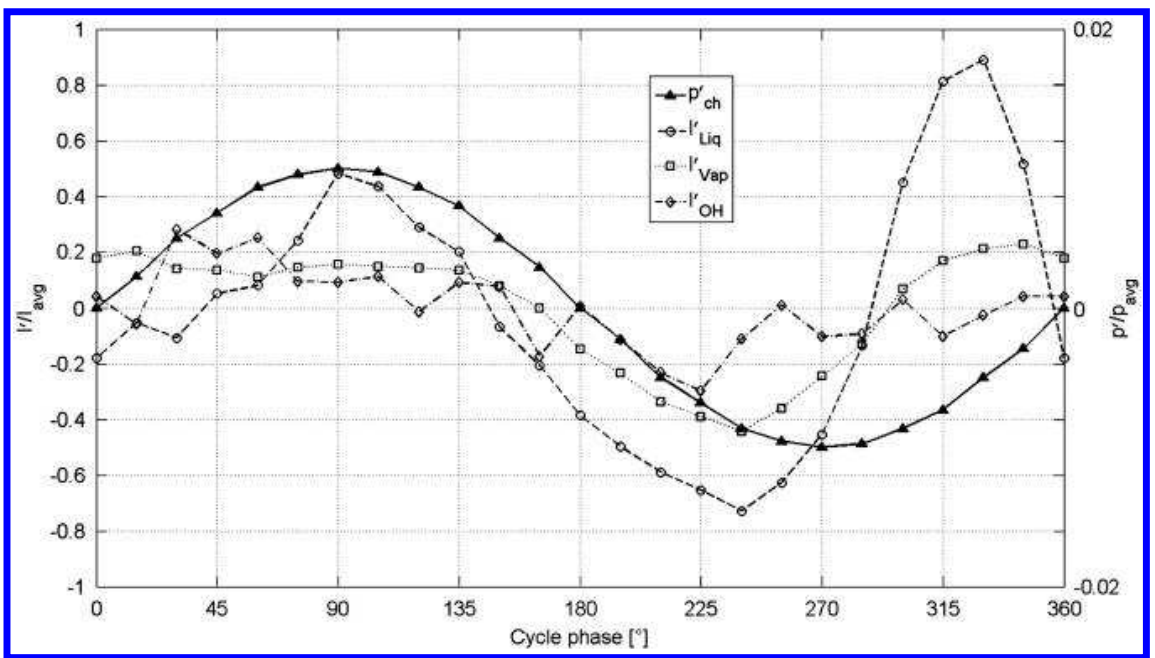

Fig. 15 Temporal sequence of the $\mathrm{OH}$ radical and kerosene fluorescence intensities during an instability cycle using phase-averaged analysis on PLIF images.

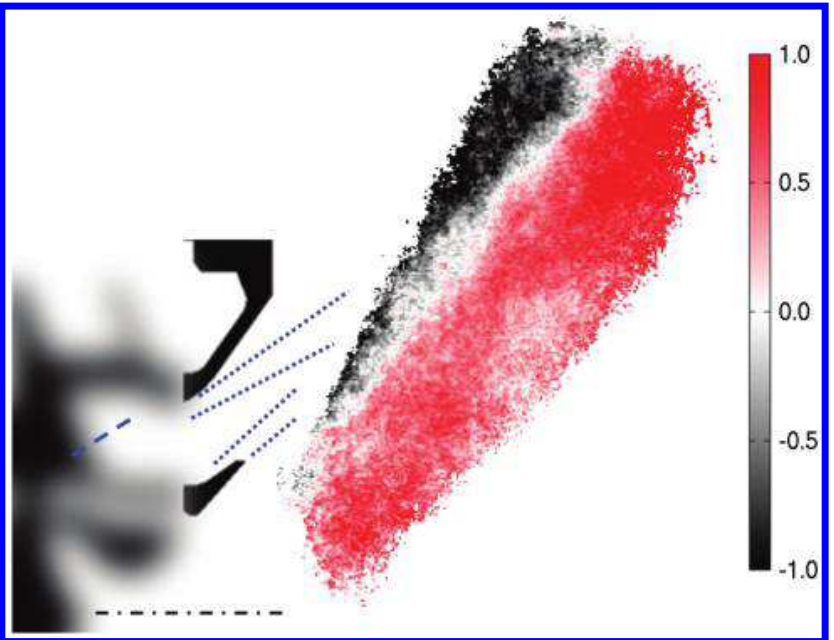

Fig. 16 Spatial distribution of the local Rayleigh index.

On the other hand, the negative local Rayleigh index values indicate a stabilizing region, contributing to damping of the instabilities due to unsteady heat release out of phase with the chamber pressure. The first conclusion that can be drawn from Fig. 16 is that the inner recirculation zone, located in the flow region between the combustor longitudinal axis and the flame front (red area), sustains instabilities. Additionally, Fig. 16 reveals the position of the flame during the cycle. The flame angle is smaller during the first half of the pressure cycle, whereas this angle is wider during the second half of the pressure cycle, when the unsteady heat release is damping the instability phenomena (black area):

$$
R a(x, r) \propto \frac{1}{T} \int_{T} p^{\prime}(x, r, t) q^{\prime}(x, r, t) \mathrm{d} t
$$

\section{Conclusions}

The experimental analysis presented in this paper on an industrial air-blast injection system used in an aeronautical combustion chamber revealed the complex unsteady behavior of the liquid phase and its contribution to the amplification of combustion instabilities. In this configuration, the liquid supplied to the injector through the pressure atomizer or jet in crossflow interacts with the walls to form liquid films that are convected toward the injector outlet and subsequently re-atomized. When the air mass flow rate fluctuates, the liquid behavior is impacted through modifications of the jet trajectories, leading to large oscillations of the spray pattern in the combustion chamber. The time delay between the pressure oscillations and the liquid entering into the combustion chamber is greatly dependent on the elementary process involved in liquid transport and atomization and on the internal geometry of the air-blast injector. It also depends on the dynamic response of the different air circuits, which is fixed by this geometry.

In combustion science, the ability to predict the occurrence of combustion instabilities is greatly dependent on the accurate determination of the phase and amplitude relationships between pressure or velocity fluctuations and the heat release from the flame. In many cases, this relationship is experimentally determined through flame transfer function measurements. Different methods are also proposed in the literature to determine this function from modeling or fluid dynamics numerical simulations. For complex geometries such as liquid-fueled combustors, the method must take into account physical phenomena specific to the dispersed phase (droplets). In particular, the spray/wall interaction and the physics of the wall film instabilities may have to be considered. This could be a great challenge for further investigations.

\section{Acknowledgments}

The research leading to these results has received funding from the European Community's Seventh Framework Program (FP7/20072013) under grant agreement ACP8-GA-2009-234009. This is part of the four-year Knowledge for Ignition, Acoustics and Instabilities project that started in May 2009, which is a European initiative financed under the FP7 and addresses innovative solutions for the development of new combustors in aeroengines. It aims at providing low NOx methodologies to be applied to design these combustors. Moreover, the successful experimental campaigns realized on the liquid-fueled ONERA thermoacoustic rig setup were made possible by the tremendous quality and energy of D. Sebbane and F. Bigot.

\section{References}

[1] Ducruix, S., Schuller, T., Durox, D., and Candel, S., "Combustion Dynamics and Instabilities: Elementary Coupling and Driving Mechanisms," Journal of Propulsion and Power, Vol. 19, No. 5, Oct. 2003, pp. 722-734. doi: $10.2514 / 2.6182$

[2] Lieuwen, T., "Modeling Premixed Combustion-Acoustic Wave Interactions: A Review," Journal of Propulsion and Power, Vol. 9, No. 5, Oct. 2003, pp. 765-781. doi: $10.2514 / 2.6193$

[3] Marble, F. E., and Candel, S. M., "Acoustic Disturbance from Gas NonUniformities Convected Through a Nozzle," Journal of Sound and Vibration, Vol. 55, No. 2, 1977, pp. 225-243. doi:10.1016/0022-460X(77)90596-X

[4] Polifke, W., Paschereit, C. O., and Döbbeling, K., "Constructive and Destructive Interference of Acoustic and Entropy Waves in a Premixed 
Combustor with a Choked Exit," International Journal of Acoustics and Vibration, Vol. 6, No. 3, 2001, pp. 135-146.

[5] Poinsot, T. J., Trouve, A. C., Veynante, D. P., Candel, S. M., and Esposito, E. J., "Vortex-Driven Acoustically Coupled Combustion Instabilities," Journal of Fluid Mechanics, Vol. 177, April 1987, pp. 265-292. doi:10.1017/S0022112087000958

[6] Candel, S., and Poinsot, T., "Interactions Between Acoustics and Combustion," Proceedings of the Institute of Acoustics, Vol. 10, No. 2, 1988, pp. 103-154.

[7] Schadow, K. C., Gutmark, E., Parr, T. P., Parr, D. M., and Wilson, K. J., "Large-Scale Coherent Structures as Drivers of Combustion Instability," Combustion Sciences and Technology, Vol. 64, Nos. 4-6, 1989, pp. $167-186$. doi:10.1080/00102208908924029

[8] Heneghan, S., Vangsness, M., Ballal, D., Lesmerises, A. L., and Sturgess, G. J., "Acoustic Characteristics of a Research Step Combustor," 26th Joint Propulsion Conference, AIAA Paper 1990-1851, July 1990 . doi:10.2514/6.1990-1851

[9] Strategic Research Agenda, Vol. 1, Advisory Council for Aeronautics Research in Europe, 2002.

[10] Higgins, B., "On the Sound Produced by a Current of Hydrogen Gas Passing Through a Tube," Journal of Natural Philosophy, Chemistry and the Arts, Vol. 1, Jan. 1802, pp. 129-131.

[11] Rijke, P., "Notice of a New Method of Causing a Vibration of the Air Contained in a Tube Open at Both Ends," Philosophical Magazine: Series 4, Vol. 17, No. 116, 1859, pp. 419-422. doi:10.1080/14786445908642701

[12] Strutt, J. W., (Lord Rayleigh), The Theory of Sound, Vol. 2, Macmillan, New York, 1878, pp. 226-230.

[13] Crocco, L., and Cheng, S., Theory of Combustion Instability in Liquid Propellant Rocket Motors, AGARDograph, Vol. 8, Butterworths, London, 1956, p. 200.

[14] Crocco, L., "Theoretical Studies on Liquid Propellant Rocket Instability," Symposium (International) on Combustion, Vol. 10, No. 1, 1965, pp. 1101-1128. doi:10.1016/S0082-0784(65)80249-1

[15] Candel, S., Durox, D., Schuller, T., Palies, P., Bourgouin, J.-F., and Moeck, J. P., "Progress and Challenges in Swirling Flame Dynamics," Comptes Rendus Mecanique, Vol. 340, Nos. 11-12, 2012, pp. $758-768$.

doi:10.1016/j.crme.2012.10.024

[16] Putnam, A., and Dennis, W., "Survey of Organ-Pipe Oscillations in Combustion Systems," Journal of the Acoustical Society of America, Vol. 28, No. 2, 1956, pp. 246-259. doi:10.1121/1.1908253

[17] Putnam, A., and Dennis, W., "Organ-Pipe Oscillations in a Burner with Deep Ports," Journal of the Acoustical Society of America, Vol. 28, No. 2, 1956, pp. 260-269. doi: $10.1121 / 1.1908255$

[18] Nicoud, F., and Poinsot, T., "Thermoacoustic Instabilities: Should the Rayleigh Criterion be Extended to Include Entropy Changes?," Combustion and Flame, Vol. 142, Nos. 1-2, 2005, pp. 153-159. doi:10.1016/j.combustflame.2005.02.013

[19] Candel, S. M., "Combustion Instabilities Coupled by Pressure Waves and Their Active Control," Symposium (International) on Combustion, Vol. 24, No. 1, 1992, pp. 1277-1296. doi:10.1016/S0082-0784(06)80150-5

[20] Shih, W.-P., Lee, J. G., and Santavicca, D. A., "Stability and Emissions Characteristics of a Lean Premixed Gas Turbine Combustor," Symposium (International) on Combustion, Vol. 26, No. 2, 1996, pp. 27712778. doi:10.1016/S0082-0784(96)80115-9

[21] Edwards, N. R., McIntosh, A. C., and Brindley, J., "The Development of Pressure Induced Instabilities in Premixed Flames," Combustion Science and Technology, Vol. 99, Nos. 1-3, 1994, pp. 179-199. doi:10.1080/00102209408935432

[22] Lieuwen, T., and Zinn, B. T., "The Role of Equivalent Ratio Oscillations in Driving Combustion Instabilities in Low NOx Gas Turbines," Symposium (International) on Combustion, Vol. 27, No. 2, 1998, pp. 18091816. doi:10.1016/S0082-0784(98)80022-2

[23] Lee, J. G., Kwanwoo, K., and Santavicca, D. A., "Measurement of Equivalence Ratio Fluctuation and Its Effect in Heat Release During Unstable Combustion," Proceedings of the Combustion Institute, Vol. 28, No. 1, 2000, pp. 415-421. doi:10.1016/S0082-0784(00)80238-6

[24] Dowling, A. P., and Hubbard, S., "Instability in Lean Premixed Combustors," Journal of Power and Energy, Vol. 214, No. 4, June 2000, pp. $317-332$.

doi:10.1243/0957650001537903

[25] Eckstein, J., Freitag, E., Hirsch, C., and Sattelmayer, T., "Experimental Study on the Role of Entropy Waves in Low Frequency Oscillations for Diffusion Burners," Proceedings of ASME Turbo Expo 2004: Power for Land, Sea, and Air, American Soc. of Mechanical Engineers Paper GT2004-54163, Fairfield, NJ, 2004, pp. 743-751.

doi:10.1115/GT2004-54163

[26] Giuliani, F., Gajan, P., Diers, O., and Ledoux, M., "Influence of Pulsed Entries on a Spray Generated by an Airblast Injection Device: An Experimental Analysis on Combustion Instability Processes in Aeroengines," Proceedings of the Combustion Institute, Vol. 29, No. 1, 2002, pp. 91-98. doi:10.1016/S1540-7489(02)80016-5

[27] Gajan, P., Strzelecki, A., Platet, B., Lecourt, R., and Giuliani, F., "Investigation of Spray Behavior Downstream of an Aeroengine Injector with Acoustic Excitation," Journal of Propulsion and Power, Vol. 23, No. 2, 2007, pp. 390-397. doi: 10.2514/1.22394

[28] Samaniego, J. M., Yip, B., Poinsot, T., and Candel, S., "Low-Frequency Combustion Instability Mechanisms in a Side-Dump Combustor," Combustion and Flame, Vol. 94, No. 4, 1993, pp. 363-380. doi:10.1016/0010-2180(93)90120-R

[29] Freitag, E., Konle, H., Lauer, M., Hirsch, C., and Sattelmayer, T., "Pressure Influence on the Flame Transfer Function of a Premixed Swirling Flame," Proceedings of ASME Turbo Expo 2006, American Soc. of Mechanical Engineers Paper GT2006-90540, Fairfield, NJ, 2006, pp. 477-486. doi:10.1115/GT2006-90540

[30] Hanson, R., "Combustion Diagnostics: Planar Imaging Techniques," Symposium (International) on Combustion, Vol. 21, No. 1, 1986, pp. 1677-1680, IN5-IN8, 1681-1691. doi:10.1016/S0082-0784(88)80401-6

[31] Orain, M., Mercier, X., and Grisch, F., "PLIF Imaging of Fuel-Vapour Spatial Distribution Around a Monodisperse Stream of Acetone Droplets: Comparison with Modeling," Combustion Science and Technology, Vol. 177, No. 2, 2005, pp. 249-278. doi: $10.1080 / 00102200590900228$

[32] Meier, U. E., Wolff-Gaßmann, D., and Stricker, W., "LIF Imaging and 2-D Temperature Mapping in a Model Combustor at Elevated Pressure," Aerospace Science and Technology, Vol. 4, No. 6, 2000, pp. 403-414. doi:10.1016/S1270-9638(00)00142-5

[33] Li, Z. S., Li, B., Sun, Z. W., Bai, X. S., and Aldén, M., "Turbulence and Combustion Interaction: High Resolution Local Flame Front Structure Visualization Using Simultaneous Single-Shot PLIF Imaging of $\mathrm{CH}$, $\mathrm{OH}$, and $\mathrm{CH} 2 \mathrm{O}$ in a Piloted Premixed Jet Flame," Combustion and Flame, Vol. 157, No. 6, 2010, pp. 1087-1096. doi:10.1016/j.combustflame.2010.02.017

[34] Orain, M., Grisch, F., Jourdanneau, E., Rossow, B., Guin, C., and Trétout, B., "Simultaneous Measurements of Equivalence Ratio and Flame Structure in Multipoint Injectors Using PLIF," Comptes Rendus Mecanique, Vol. 337, Nos. 6-7, 2009, pp. 373-384. doi:10.1016/j.crme.2009.06.019

[35] Orain, M., Grisch, F., and Verdier, H., "Measurements of Fuel Distribution and Flame Structure in Kerosene-Fuelled Combustors Using Planar Laser-Induced Fluorescence and $\mathrm{OH} *$ Emissions," ILASS - Europe 2010, 23rd Annual Conference on Liquid Atomization and Spray Systems, edited by Forman, M., Jedelský, J., Katolický, J., Jícha, M., Krejčí, V., Hejčík, J., and Fišer, J., Elsevier Masson SAS, New York, Sept. 2010, Paper 73.

[36] Armitage, C., Balachandran, R., Mastorakos, E., and Cant, R., "Investigation of the Nonlinear Response of Turbulent Premixed Flames to Imposed Inlet Velocity Oscillations," Combustion and Flame, Vol. 146, No. 3, 2006, pp. 419-436.

doi:10.1016/j.combustflame.2006.06.002

[37] Bellows, B., Bobba, M., Seitzman, J., and Lieuwen, T., "Nonlinear Flame Transfer Function Characteristics in a Swirl Stabilized Combustor," Journal of Engineering for Gas Turbines and Power, Vol. 132, No. 4, 2007, pp. 954-961. doi: $10.1115 / 1.2720545$

[38] de la Cruz Garcia, M., Mastorakos, E., and Dowling, A., "Investigations on the Self-Excited Oscillations in a Kerosene Spray Flame," Combustion and Flame, Vol. 156, No. 2, Feb. 2009, pp. 374-384. doi:10.1016/j.combustflame.2008.11.018

[39] Giezendanner, R., Keck, O., Weigand, P., Meier, W., Meier, U., Stricker, W., and Aigner, M., "Periodic Combustion Instabilities in a Swirl Burner Studied by Phase-Locked Planar Laser-Induced Fluorescence," Combustion Science and Technology, Vol. 175, No. 4, 2003, pp. 721- 
741.

doi: $10.1080 / 00102200302390$

[40] Güthe, F., and Schuermans, B., "Phase-Locking in Post-Processing for Pulsating Flames," Measurement Science and Technology, Vol. 18, No. 9, 2007, pp. 3036-3042. doi:10.1088/0957-0233/18/9/039

[41] Kopp-Vaughan, K., Tuttle, S., Renfro, M., and King, G., "Heat Release and Flame Structure Measurements of Self-Excited AcousticallyDriven Premixed Methane Flames," Combustion and Flame, Vol. 156, No. 10, 2009, pp. 1971-1982. doi:10.1016/j.combustflame.2009.06.018

[42] Providakis, T., Zimmer, L., Scouflaire, P., and Ducruix, S., "Effect of Fuel Distribution on Spray Dynamics in a Two-Staged Multi-Injection Burner," Proceedings of ASME Turbo Expo 2011, American Soc. of Mechanical Engineers Paper GT2011-46519, Fairfield, NJ, 2011. doi:10.1115/GT2011-46519

[43] Le Gal, P., Farrugia, N., and Greenhalgh, D., "Laser Sheet Dropsizing of Dense Sprays," Optics and Laser Technology, Vol. 31, No. 1, 1999, pp. 75-83. doi:10.1016/S0030-3992(99)00024-9

[44] Lee, S.-Y., Seo, S., Broda, J., Pal, S., and Santoro, R., "An Experimental Estimation of Mean Reaction Rate and Flame Structure During Combustion Instability in a Lean Premixed Gas Turbine Combustor," Proceedings of the Combustion Institute, Vol. 28, No. 1, 2000, pp. 775782. doi:10.1016/S0082-0784(00)80280-5
[45] Hammack, S., Kostka, S., Lynch, A., Carter, C., and Lee, T., "Simultaneous 10-kHz PLIF and Chemiluminescence Imaging of $\mathrm{OH}$ Radicals in a Microwave Plasma-Enhanced Flame," IEEE Transactions on Plasma Science, Vol. 41, No. 12, 2013, pp. 3279-3286. doi:10.1109/TPS.2013.2280729

[46] Yamada, T., Johchi, A., and Zimmer, L., "Gradient-Based Filtering Operations for Flame Front Analysis from OH PLIF Images in a Liquid Fuelled Combustor," 16th International Symposium on Applications of Laser Techniques to Fluid Mechanics, edited by Durão, D. F. G., Hishida, K., Longmire, E. K., Moreira, A. L. N., and Tropea, C., Springer-Verlag, New York, July 2012, Paper 3.14.2.

[47] Lubarsky, E., Shcherbik, D., Bibik, O., Gopala, Y., and Zinn, B. T., "Fuel Jet in Cross Flow-Experimental Study of Spray Characteristics, Advanced Fluid Dynamics," Advanced Fluid Dynamics, edited by Oh, H. W., InTech, Rijeka, Croatia, 2012, pp. 4-80. doi: $10.5772 / 26045$

[48] Najm, H. N., Paul, P. H., Mueller, C. J., and Wyckoff, P. S., "On the Adequacy of Certain Experimental Observables As Measurements of Flame Burning Rate," Combustion and Flame, Vol. 113, No. 3, 1998, pp. 312-332. doi:10.1016/S0010-2180(97)00209-5

J. Seitzman Associate Editor 